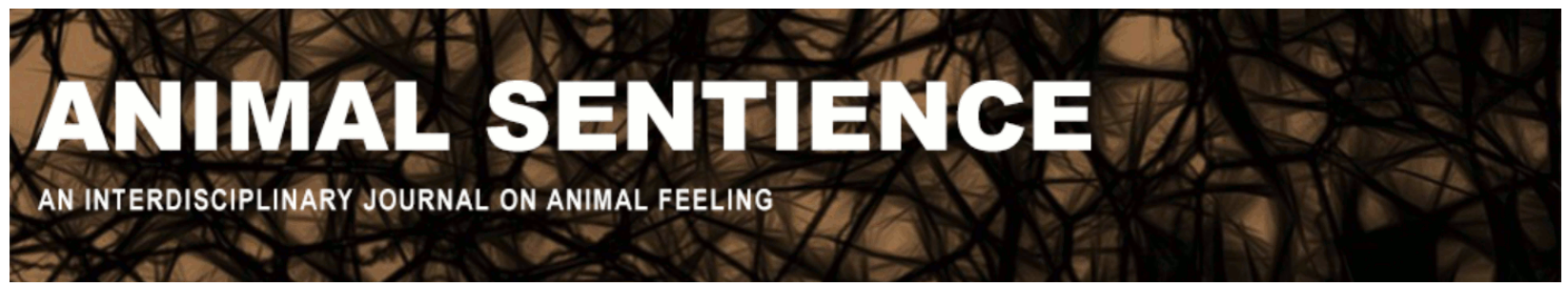

Jung, Christoph (2019) Why cod don't like to sunbathe: Quantity and quality in the animal kingdom. Animal Sentience 23(49)

DOI: $10.51291 / 2377-7478.1457$

Date of submission: 2019-05-25

Date of acceptance: 2019-06-01

(c) $\underset{\mathrm{EY}}{\mathrm{C}}$

This article has appeared in the journal Animal

Sentience, a peer-reviewed journal on animal

cognition and feeling. It has been made open access,

free for all, by WellBeing International and deposited

in the WBI Studies Repository. For more information,

please contact

wbisr-info@wellbeingintl.org.

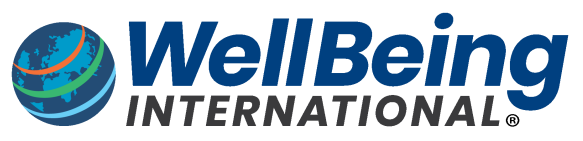

SOLUTIONS FOR PEOPLE, ANIMALS AND ENVIRONMENT 


\title{
Why cod don't like to sunbathe: Quantity and quality in the animal kingdom
}

Commentary on Chapman \& Huffman on Human Difference

\author{
Christoph Jung \\ Petwatch
}

\begin{abstract}
The difference between a cod and a lizard is not just a quantitative one. The recognition of qualitative differences between species does not imply a moral ranking. Our species' special abilities to shape the earth mean we have a special responsibility for ensuring a liveable future for all organisms, human and non-human.
\end{abstract}
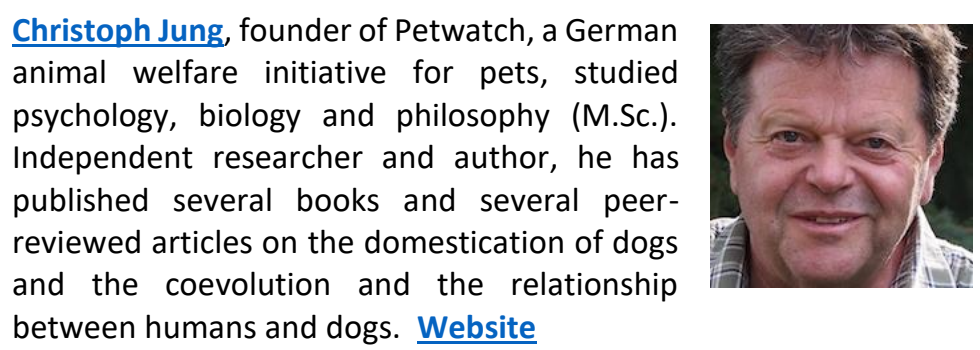

Let's imagine there were no qualitative differences between species. Why do cod love to swim as a group in the deep, ice-cold water of the North Atlantic and why do lizards love to sunbathe alone on a dry rock? If we switched their biotopes, both species would die miserably within minutes. For Chapman \& Huffman (2018) (C \& H), this would be the consequence of just quantitative differences: "just as there are differences (and similarities) between any two species, any two cultures, or even any two individuals." Can we really understand the wonderful diversity of nature with such categories?

Hegel (2010) and later Engels $(1934,1940)$ developed the dialectical principle of the transition from quantity to quality and vice versa. A torn hair does not make a bald head, but many torn hairs do. The change from quantity to quality is somewhere in between. On the evolutionary path from monkey to primate to Homo sapiens, there are many small steps that eventually lead to qualitative differences (Iotchev \& Costa, 2019). It is a new quality that has enabled Homo sapiens to make our planet increasingly customized for our own species' use, deforming it for other species. Transition from quantity to quality is not a moral category from worse to better, worthless to valuable.

$\mathrm{C} \& \mathrm{H}$ suggest that the use of tools would not be an example of a qualitative difference. Goodall (1964) was the first to describe how chimpanzees use branches as utensils. Today we know many more species use something like tools (Hall \& Schaller, 1964; Hart \& Hart, 1994). But what non-human animal produces millions of cars and ships that change the whole image of nature. Using a simple branch that lies nearby does not have the same quality. Somewhere there must have been a leap from quantity to quality in using and making tools.

Since Homo erectus, all human beings have walked upright (Bennett et al., 2009), leaving their hands free. They produced stone tools such as hand axes or wooden ones like spears. These tools were manufactured in an elaborate process, independent of their direct application. The production technique is not simple. I think most people today would fail in manufacturing a hand axe from a flint stone. But one thing we still master today, and better than ever: in all cases, the 
purpose of the production is represented in advance in our human brain. The benefit is not immediate. It is thus that we work for money. We cannot eat money, yet it determines our motivation and much of our thinking as well. We have not yet seen this feature invented and used spontaneously in non-human animals (although an approximation can be induced by training) (Sousa \& Matsuzawa, 2001)

The recognition of qualitative differences between species does not necessarily imply a moral order of precedence. Homo sapiens is unique but not superior to the others. Actually, we are ignorant and stupid, surely never a divine image. The axiom that man was born as sovereign of the world, that humans are made in the image of a god and given dominion over "lower creatures" (Genesis) is simply a human-made ideology. This ideology is ultimately directed against humankind itself. We need nature existentially. Nature does not need the newcomer, Homo sapiens. We would do very well to become humble and understand ourselves as a small part of a great nature, as our ancestors did in the Stone Age and likely millennia before (Ehmer, 1994).

At the same time, we should take responsibility - the special responsibility that is rooted in our special abilities to shape the earth through our unique qualities and our unique power as a worldwide human community. We have superior skills in thinking and building machines. As human beings, we only have a future if we treat the non-human living beings as companions with respect and real care. I hope that our "superior quality" will be strong enough, to provide a future for our children and that necessarily means exactly the same livable future for all animals human or non-human - and the whole of nature as well. We have only one future: together.

\section{References}

Bennett, M., Harris, J., Richmond, B., Braun, D., Mbua, E., Kiura, P., Olago, D., Kibunjia, M., Omuombo, C., Behrensmeyer, A., Huddart, D., \& Gonzalez, S. (2009, 27 Feb.). Early hominin foot morphology based on 1.5-million-year-old footprints from lleret, Kenya. Science, 323(5918), 1197-1201.

Chapman, C. A., \& Huffman, M. A. (2018). Why do we want to think humans are different? Animal Sentience 23(1).

Darwin, C. (1859). On the origin of species by means of natural selection, or, the preservation of favoured races in the struggle for life. London: John Murray.

Ehmer, M. (1994). Göttin Erde: Kult und Mythos der Mutter Erde. Berlin: Zerling.

Engels, F. (1934). The part played by labour in the transition from ape to man. Progress Publishers: Moscow.

Engels, F. (1940). Dialectics of nature. New York: International Publishers.

Goodall, J. (1964). Tool-using and aimed throwing in a community of free-living chimpanzees. Nature, 201, 1264.

Hall, K., \& Schaller, G. B. (1964). Tool-using behavior of the California sea otter. Journal of Mammalogy, 45, 287-298.

Hart, B. L., \& Hart, L. A. (1994). Fly switching by Asian elephants: Tool use to control parasites. Animal Behaviour, 48, 35-45.

Hegel, G. W. F. (2010). Encyclopedia of the philosophical sciences in basic outline. Cambridge: Cambridge University Press.

lotchev, I. B., \& Costa, K. M. (2019). Quantity has a quality of its own. Animal Sentience 23(44).

Sousa, C., \& Matsuzawa, T. (2001). The use of tokens as rewards and tools by chimpanzees (Pan troglodytes). Animal Cognition, 4(3-4), 213-221. 